\title{
NILAI-NILAI PENDIDIKAN DALAM KOMUNIKASI KEJHUNG MADURA DAN RELEVANSINYA BAGI PENANAMAN KARAKTER BERBASIS KEARIFAN LOKAL MADURA
}

\author{
Sri Utami \\ Victor Maruli T L.Tobing \\ FKIP, Universitas Dr. Soetomo Surabaya \\ Utamisri08@gmail.com
}

\begin{abstract}
ABSTRAK
Gaya nyanyian Madura atau dikenal dengan sebutan kèjhungan pengekspresian yang menggebu, terkesan spontan,dan menyukai permainan nada-nada tinggi yang kemudian membentuk polapola melodi yang disebut kellèghãn. Karakteristik kèjhungan yang relatif berbeda dengan kultur nyanyian daerah lainnya. Kèjhung (Kidung dalam bahasa Jawa) merupakan tradisi lisan Madura. Sebagai sebuah tradisi lisan, kèjhung menjadi salah satu ikon "manusia" Madura dari sudut pandang relegi, sosial, ekonomi, dan politik yang diungkapkan dengan bahasa puitis. Hal inilah yang menjadikan kèjhung Madura tetap dilestarikan dalam berbagai bentuk tradisi lisan Madura. Penelitian ini menggunakan metode deskriptif dengan pendekatan kualitatif deskriptif. Model analisis yang digunakan dalam kerangka penelitian tradisi lisan kèjhung Madura ini mencakup dua tahap yakni (1) etnopedagogi untuk mengeksplorasi nilai-nilai pendidikan karakter berbasis kearifan lokal. (2) hermeneutika untuk menemukan relevansi bagi penanaman karakter. Nilainilai pendidikan yang terkadung dalam kèjhung Madura tersebut meliputi (1) nilai religius, (2) nilai budaya, (3) nilai sosial, (4) nilai personal. Kejhung Madura memiliki relevansi untuk menanamkan nilai-nilai luhur untuk membentuk karakter masyarakat. Penanaman karakter dapat dilakukan dengan melalui pertunjukan atau dapat diadopsi dalam bentuk baru dengan media yang disesuaikan dengan kondisi perkembangan teknologi pada saat ini dan melalui pendidikan seni budaya, pendidikan muatan lokal, pendidikan sastra dengan memasukkan nilai-nilai karakter budaya lokal dan dapat disosialisasi dan ditanamkan kepada anak didik di sekolah.
\end{abstract}

Key Word: Nilai Pendidikan, kèjhung Madura, Kearifan lokal

\section{ABSTRACT}

Madura chanting style or known as the kèjhungan expression of passionate, impressed spontaneous, and love the game high notes that then form melodic patterns called kellèghãn. The characteristics of kèjungan are relatively different from other regional singing cultures. Kèjhung (Song in Javanese) is an oral tradition of Madura. As an oral tradition, kèjhung became one of Madura's "human" icons from a social, economic, and political standpoint expressed in poetic language. This is what makes Madura kejhung preserved in various forms of Madurese oral tradition. This research uses descriptive method with descriptive qualitative approach. The analytical model used in the research framework of the oral tradition of kèjhung Madura includes two stages: (1) ethnopedagogy to explore the values of character education based on local wisdom. (2) hermeneutics to find relevance for character planting. The educational values contained in the Madura kèjhung include (1) religious values, (2) cultural values, (3) social values, (4) personal values. Kejhung Madura has relevance to instill noble values to form the character of society. Character planting can be done through the show or can be adopted in a new form with media adapted to current technological developments and through cultural arts education, local content education, literary education by incorporating local cultural character values and can be socialized and embedded into students in school

Key Word: Educational Value, kèjhung Madura, Local Wisdom 


\section{PENDAHULUAN}

Masyarakat Madura memiliki cara pandang dan perlakuan yang khas untuk memuliakan tuhan, orang tua, guru, dan pemerintah, hal tersebut terkandung dalam falsafah Madura Babbak, Babbu', Guru, Rato (Bapak, Ibu, Guru, dan pemerintah. Cara pandang tersebut selain sudah ditanamkan ke dalam sebuah ungkapan falsafah, juga ditanamkan dalam kepribadian masyarakat Madura sejak dini. Tujuan tidak lain agar gengerasi-generasi penerus tersebut mempunyai cara pandang yang luhur terhadap sosok yang dimulyakan seperti bapak dan ibu, guru, dan pemerintah.

Kèjhung (Kidung dalam bahasa Jawa) merupakan tradisi lisan Madura. Sebagai sebuah tradisi lisan, kèjhung menjadi salah satu ikon "manusia" Madura dari sudut pandang relegi, sosial, ekonomi, dan politik yang diungkapkan dengan bahasa puitis. Hal inilah yang menjadikan kèjhung Madura tetap dilestarikan dalam berbagai berntuk tradisi lisan Madura (Bouvier, 2007:22). Tradisi lisan yang masih menggunakan kèjhung Madura yaitu (1) rokat atau ruwatan, (2) tayuban atau dalam istilah masyarkat Madura disebut juga sebagai tandha', (3) soronen atau juga disebut sebagai musik tradisional Madura, (4) ludruk, (5) Damong Gardam dan Sandhur atau juga disebut sebagai tradisi lisan yang lebih menonjolkan kesan ritual, dan (6) SapeSono' dan Kerrabhên Sape.

Keenam tradisi lisan tersebut memiliki bentuk kèjhung yang sangat beragam. Kèjhung ritual terdapat dalam tradisi lisan rokat terutama rokat buju', kèjhung bhâbulangan (pendidikan) hampir terdapat dalam semua tradisi lisan Madura, kèjhung percintaan terdapat dalam tayuban, dan kèjhung satiran terdapat dalam ludruk.
Masing-masing kèjhung tersebut terdapat pandangan hidup atau falasah masyarkat Madura yang oreintasinya berbeda. Oreintasi tersebut menjadi ciri khas masyarakat Madura dalam berpikir, bersikap dan berperilaku

\section{LANDASAN TEORI}

\section{Pengertian Folklor}

Folklor merupakan bagian dari tradisi lisan dan salah satu bentuk ekspresi kebudayaan daerah yang jumlahnya beratusratus di seluruh Indonesia. Sementara tradisi lisan memiliki keterkaitan dengan sastra tulisan yang fungsinya dalam sastra sebagai performing art. Selanjutnya Folklor, dapat dibagi menjadi tiga, yaitu (1) verbal folklore (folklor lisan), (2) partly verbal (folklor setengah lisan), dan (3) non verbal folklore (folklor bukan lisan).

Hal ini dapat dimengerti mengingat bahwa banyak folklor yang mempunyai proyeksi emosi manusia yang paling jujur manifestasinya (Danandjaja, 1997:3). Untuk memperjelas apa yang dikemukakan tersebut, Danandjaja membentuk folklor lisan ke dalam kelompok besar yaitu 1) Bahasa rakyat (folk speech), seperti logat, julukan, pangkat tradisional, dan titel kebangsawanan. 2) Ungkapan tradisional, seperti peribahasa, pepatah, dan pomeo, 3) Pertanyaan tradisional, seperti teka-teki, 4) Puisi rakyat seperti pantun, gurindam, dan syair. 5) Cerita pusaka rakyat, seperti mite, legenda, dan dongeng, 6) Nyanyian rakyat.

\section{Konsep Kearifan Lokal}

Kearifan Lokal Kearifan lokal (local wisdom) dalam disiplin antropologi dikenal juga dengan istilah local genius. Local genius ini merupakan istilah yang mula 
pertama dikenalkan oleh Quaritch Wales. (Ayatrohaedi, 1986). Para antropolog membahas secara panjang lebar pengertian local genius ini. Antara lain Haryati Soebadio mengatakan bahwa local genius adalah juga cultural identity, identitas/kepribadian budaya bangsa yang menyebabkan bangsa tersebut mampu menyerap dan mengolah kebudayaan asing sesuai watak dan kemampuan sendiri (Ayatrohaedi, 1986:18-19).

Ciri-ciri kearifan lokal tersebut adalah sebagai berikut: 1) mampu bertahan terhadap budaya luar, 2) memiliki kemampuan mengakomodasi unsur-unsur budaya luar, 3) mempunyai kemampuan mengintegrasikan unsur budaya luar ke dalam budaya asli, 4) mempunyai kemampuan mengendalikan, 5) mampu mem-beri arah pada perkembangan budaya.

Oleh karena itu, sangat beralasan jika dikatakan bahwa kearifan lokal merupakan entitas yang sangat menentukan harkat dan martabat manusia dalam komunitasnya. Hal itu berarti kearifan lokal yang di dalamnya berisi unsur kecerdasan kreativitas dan pengetahuan lokal dari para elit dan masyarakatnya adalah yang menentukan dalam pembangunan peradaban masyarakatnya. Kearifan lokal dapat ditemui dalam nyanyian, pepatah, sasanti, petuah, semboyan, pantun, dan kitab-kitab kuno yang melekat dalam perilaku sehari-hari. Kearifan lokal biasanya tercermin dalam kebiasaan-kebiasaan hidup masyarakat yang telah berlangsung lama.

\section{Konsep Nilai}

Nilai adalah sesuatu yang berharga, bermutu, menunjukkan kualitas, dan berguna bagi manusia. Sesuatu itu bernilai berarti sesuatu itu berharga atau berguna bagi kehidupan manusia. Sifat-sifat nilai menurut Daroeso (dalam Kalangie, 1994) adalah sebagai berikut: 1) nilai itu suatu realitas abstrak dan ada dalam kehidupan manusia. Nilai yang bersifat abstrak tidak dapat diindra. Hal yang dapat diamati hanyalah objek yang bernilai. 2) Nilai memiliki sifat normatif, artinya nilai mengandung harapan, cita-cita, dan suatu keharusan sehingga nilai nemiliki sifat ideal. Nilai diwujudkan dalam bentuk norma sebagai landasan manusia dalam bertindak. 3) Nilai berfungsi sebagai daya dorong dan manusia adalah pendukung nilai. Manusia bertindak berdasar dan didorong oleh nilai yang diyakininya. Dalam filsafat, nilai dibedakan dalam tiga macam, yaitu: 1) nilai logika adalah nilai benar salah; 2) nilai estetika adalah nilai indah tidak indah; dan 3) nilai etika/moral adalah nilai baik buruk. Nilai moral adalah suatu bagian dari nilai, yaitu nilai yang menangani kelakuan baik atau buruk dari manusia. Moral selalu berhubungan dengan nilai, tetapi tidak semua nilai adalah nilai moral. Moral berhubungan dengan kelakuan atau tindakan manusia. Nilai moral inilah yang lebih terkait dengan tingkah laku kehidupan kita sehari-hari. Nilai religius yang merupakan nilai kerohanian tertinggi dan mutlak serta bersumber pada kepercayaan atau keyakinan manusia.

\section{Nilai Pendidikan}

Nilai pendidikan adalah segala sesuatu yang mendidik ke arah kedewasaan (Nashir, 2013:93). Dalam hal ini proses pendidikan berarti bukan hanya dapat dilakukan dalam satu tempat dan suatu waktu melainkan pendidikan dapat dilakukan dengan pemahaman, pemikiran, dan penikmatan karya sastra. Nilai-nilai pendidikan itu dapat berupa nilai moral, nilai religius, nilai 
sosial, nilai budaya, nilai personal, dan lain-lain. Oleh karena itu, nilai pendidikan sangat erat kaitannya dengan karya sastra. Kenyataan yang disajikan sastra bukanlah untuk diperiksa kebenarannya terhadap alam nyata, melainkan bersifat menghimbau pembacanya untuk menyelam dan bilamana perlu menggali untuk menemukan sesuatu, yaitu nilai (Sumardi, 1992: 199) langsung seperti halnya ilmu kimia melainkan harus dengan pemahaman dan pengkajian karya sastra. Karya sastra sebagai pengemban nilai-nilai pendidikan diharapkan fungsinya untuk memberikan pengaruh positif terhadap cara berpikir pembaca mengenai baik dan buruk, benar dan salah. Nilai-nilai pendidikan yang tersirat dalam berbagai hal dapat mengembangkan masyarakat dengan berbagai dimensinya dan nilai-nilai tersebut mutlak dihayati dan diresapi manusia sebab ia mengarah pada kebaikan dalam berpikir dan bertindak sehingga dapat memajukan budi pekerti serta pikiran/intelegensinya. Pendidikan agama, sosial, dan personal merupakan fokus utama dalam setiap karya sastra.

\section{METODE PENELITIAN}

Secara metodologis, penelitian ini menggunakan metode deskriptif dengan pendekatan kualitatif etnografi. Gagasan metode penelitian ini mengacu pada Spradley (1979:11-12) dan Strauss \& Corbin (1990:17-18) yang menyatakan bahwa untuk mengungkap nilai-nilai kearifan lokal dari suatu tradisiperlu digunakan metode kualitatif etnopedagogi dengan karakteristik sumber data berlatar alami dan peneliti berfungsi sebagai human instrument. Berkaitan dengan hal itu, penelitian ini melibatkan metode analisis etnopedagogi dan struktural hermeneutika. Struktural-hermeneutika digunakan untuk mengungkap kondisi konteks. Metode analisis data penelitian tradisi lisan ini dilakukan dengan menerapkan teori keilmuan sesuai dengan latar belakang peneliti atau fokus kajian yang ditetapkan yakni tradisi lisan. Oleh karena itu, teori pelengkap yang digunakan untuk analisis adalah teori struktural hermeneutika. Teori struktural hermeneutika dan etno pedagogi digunakan untuk menganalisis nilai-nilai pendidikan berbasis kearifan lokal bentuk Teks dan relevansinya terhadap penanaman karakter

\section{HASIL DAN PEMBAHASAN}

\section{Nilai-Nilai Pendidikan dalam Tradisi Lisan Kejhung Madura}

Data yang digunakan dalam penyusunan nilai pendidikan dalam tradisi lisan kejhung madura bersumber dari kesenian Tayuban dan Ludruk Madura. Nilai-nilai pendidikan itu dikelompokkan menjadi empat kelompok, yaitu (1) nilai religius, (2) nilai budaya, (3) nilai sosial, (4) nilai personal.

\section{1) Nilai Relegius}

Nilai religius adalah nilai tawakal dan berserah diri kepada Tuhan, religius. Dalam kehidupan sehari-hari masyarakat Madura cenderung memiliki sikap pasrah kepada Tuhan. Sikap pasrah tersebut tidak hanya ungkapan dalam tataran lisan saja, melainkan juga dalam setiap pekerjaan. Ungkapan yang paling terkenal dalam hal ini ialah tina apa can Allah (sudahlah apa katanya Allah) yang sering diucapkan oleh anak atau orang tua yang hendak menikahkan anakknya. Meski usia anak yang bersangkutan masih 
dini (lima belas tahun) dan laki-lakinya delapan belas tahun dan belum mempunyai pekerjaan, tetapi keduanya sudah ingin membina rumah tangga ungkapan tina apa can Allah akan selalau didengungkan keada siapa saja yang mencoba mengingatkan atau membatalkan pernikahan tersebut karena usianya masih dini. Bagi masyarkat Madura rasa kepasrahan kepada tuhan merupakan hal yang tidak bisa ditoleransi. Semboyan pasrah seperti dalam kejhung "e dimma kennengan asalla e jediyapamoleanna" mengharuskan orang Madura untuk selalu ingat tentang asal mulanya dan kamana dia harus kembali. Musibah dan cobaan betul-betul disikapi dengan qona'ah, sehingga akan menjadi sebuah kebaikan yang baru. Sikap pasrah orang Madura juga dapat dilihat dari posisi rumah dan posisi tidurnya. Di sisi lain tidak semua masyarakat Madura memiliki sikap pasrah. Selain itu, masyarakat Madura merupakan masyarakat yang religius, tidak melupakan salat karena dengan salat bisa dipakai untuk kebahagiaan dunia akhirat.

Sikap tawakal dan berserah diri masyarakat Madura terlihat dalam contoh kejhung berikut

Parjhughena toju' asela $\mid$ Ma'le e tero bi' nak potona $\mid$ E dimma kennengan asalla $\mid$ e jediya pamoleanna

Sikap religius dan selalu mengamalkan syahadat terlihat dalam kejhung berikut:

Solat maghrib tello raka'at | Pokol ennem ja'patellat | Parenta wajib torè pata'at | Ollè senneng e akherat

\section{2) Nilai Budaya}

Manusia dalam hidupnya mempunyai masalah yang harus dipecahkan secara individu dan ada yang harus dipecahkan bersama sama dengan orang lain. Nilai budaya dalam hubungan manusia dengan masyarakat dalam Kejhung Madura adalah nilai gotong royong, musyawarah, keadilan, kepatuhan, dan kebijak-sanaan.

Etnik Madura memiliki pandangan kemasyarakatan. Pandangan kemasyarakatan tersebut antara lain: bangga akan identitas; tolong-menolong; dan kebersamaan dan persatuan, sopan santun. Hal tersebut terlihat dari contoh Kejhung di bawah ini yang memperilihatkan seseorang jika sudah menjabat, atau berkedudukan harus bersikap sopan, santun agar bisa dicontoh masyarakat.

Èntar mèkat ka nambakor | Arè satto mellè karakat | Règ apangkat pa andab asor | Ma'è conto ban masarakat

Masyarakat Madura untuk senantiasa bangga akan tanah kelahiran kekayaan seni budaya dan budaya sopan santun, tanah kelahiran merupakan tanah tumpah darah yang mesti diakui karena kemuliaannya serta merupakan tempat para pahlawan,orang yang berbudi pekerti luhur dan dekat dengan yang spiritual dan ilahiah. Hal ini sesuai dengan ungkapan Madura, yaitu basa nantowagibangsa(bahasa menentukan bangsa) yang bermakna keharusan untuk selalu mengakui dan bangga akan identitas yang melekat pada diri. Sebagai masyarakat yang komunal, etnik Madura tidak akan pernah absen dari budaya tolong-menolong antarsesama. Filsafat etnik Madura yang tertuang dalam peribahasa rampa' naong baringin korong ditunjukkan kepada orang kaya yang gemar menolong yang lemah (Ashadi dan Al-Farouk, 1992:83). Madura sebagai salah satu etnik di Indonesia juga memiliki istilah song-osong lombung, jungrojung, pak-opak eling se ekapajung untuk menolong antarsesama. Pak-opak eling 
memiliki makna tolong-menolong untuk mengingatkan mereka yang lupa (berbuat salah atau berperilaku tidak baik). Ungkapan Madura yang menunjukkan budaya tolongmenolong masyarakat etnik Madura antara lain berbunyi, mon bagus pabagas (kalau tampan harus gagah) yang bermakna seseorang yang rupawan harus memiliki semangat keperwiraan dengan berkorban untuk kepentingan masyarakat (Imron, 2001). Dalam pandangan keber-saaan dan persatuan, etnik Madura percaya bahwa kebersamaan merupakan hal yang dapat membuat komunitas mereka bersatu.

\section{3) Nilai Sosial}

Nilai sosial dalam hubungan dengan orang lain adalah hidup rukun, kesopanan, menepati janji, kesetiaan, kepatuhan terhadap orang tua. Masyarakat Madura juga memiliki cara pandang dan perlakuan yang khas untuk memuliakan orang tua, guru, dan pemerintah, hal tersebut terkandung dalam falsafah Madura Babbak, Babbu', Guru, Rato (Bapak, Ibu, Guru, dan pemerintah. Cara pandang tersebut selain sudah ditanamkan ke dalam sebuah ungkapan falsafah, juga ditanamkan dalam kepribadian masyarakat Madura sejak dini. Tujuan tidak lain agar generasi-generasi penerus tersebut mempunyai cara pandang yang luhur terhadap sosok yang dimulyakan seperti bapak dan ibu, guru, dan pemerintah.

Orang madura selalu berhati-hati dalam berkata-kata atau berbicara karena perkataan tidak jauh berbeda dengan perbuatan. Terlihat dalam kutipan berikut

Ga 'lagguna ka kompolan | Sèkonèng roko' perdana | Gunana noro'è èkompola |Ollè onè ka tatakrama

Orang akan dihormati atau dihina karena perkataannya. Ketika berbicara harus menggunakan tatakrama yaitu harus melihat dengan siapa kita berbicara.

Sikap rukun dengan tetangga juga selalu dijunjung tinggi oleh orang Madura karena dengan hidup rukun maka hidupnya akan bahagia. Sikap rukun terlihat dalam kejhung berikut:

Ngala' anda njarè sokon | Nem-enem da' tèmorra | Atatangga torè parukun | Ollè senneng saomorra

\section{4) Nilai Personal}

Manusia selain sebagai makhluk sosial juga sebagai makhluk individu. Manusia dalam hidupnya mempunyai keterkaitan dengan sesamanya juga terdapat hal yang sfatnya individu. Manusia sebagai makhluk individu bukan berarti manusia sebagai keseluruhan yang tidak dapat dibagi melainkan sebagai kesatuan yang terbatas yaitu sebagai manusia perorangan. Manusia berbudaya itu mengenal dirinya, berunding dengan dirinya, sehingga tak tergantung secara mutlak dari sekelilingnya.

Nilai kepribadian hubungan manusia dengan diri sendiri dalam tradisi lisan Kejhung Madura mencakup nilai budaya kerja keras, mawas diri, berkemauan keras, keteguhan, dan sikap regas.

Pandangan hidup etnik Madura terhadap pribadi terlihat pada contoh Kejhung di bawah ini:

Lir saalir kung: Mellè topa'ka jhârâjâ | Nalèka osom anyè | Lir saalir kung: Mon akopa'nang salajâ $\mid$ La tantona ta'amonyè

Jika dalam menyelesaikan suatu perkara, hanya mendengarkan suara sepihak saja, maka sudah barang tentu langkah 
tersebut merupakan suatu tindakan yang tidak adil.

Dalam kehidupan sehari-hari, etnik Madura memiliki pandangan terhadap pribadi berperilaku adil, penjagaan diri dari perilaku buruk; dan penjunjung tinggian martabat. Etnik Madura memiliki keyakinan bahwa untuk mencapai kesuksesan di dunia, setiap orang mesti bekerja keras. Manusia mesti bekerja keras untuk menyambung hidup yang serba tidak pasti. Hal itu sekaligus menunjukkan bahwa ketidakpastian hidup di dunia inimerupakan ujian bagimanusia.. Oleh karena itu, manusia harus adil menghadapi masalah. Jika tidak, manusia akan terjebak pada perilaku buruk. Masyarakat etnik Madura percaya bahwa setiap perilaku buruk dapat berdampak buruk. Amarah dapat menimbulkan perkelahian, sedangkan perkelahian akan berdampak pada keluarga, misalnya orang tua akan bersedih karena perkelahian tersebut.. Kutipan Reng towal Asandadut e penggir labang'/Tampah cangkem...!!! menunjukkan bahwa orang lain (orang tua) akan rugi (bersedih) karena carok (perilaku buruk). Untuk mencapai kehidupan yang sempurna, masyarakat etnik Madura percaya bahwa manusia harus menjunjung tinggi martabat.. Dalam hal ini adat (tradisi) adalah salah satu hal yang mesti dijaga sesuai dengan kerangka moral yang tertera di dalam buku Baburugan Becce' (dalam Imron, 2011).

Masyarakat Madura juga selalu bersyukur dengan apa yang diterima. Sikap bersyukur tersebut digambarkan dalam contoh kejhung berikut:

Mon ka' ngangka' asorongan | Ka tartè ban torè pasaè | Sè èkoca'tebbel iman | Sadaja ujiyan torè sokkorè
Itu perlambang manusia yang telah matang dalam meresapi asam garam kehidupan. Hal itu perlu dijadikan cermin. Ketika bernasib baik, sesekali perlu sadari bahwa satu ketika akan mengalami nasib buruk yang tidak kita harapkan. Dengan demikian tidak terlalu bergembira sampai lupa bersyukur kepada Allah. Ketika nasib sedang buruk, bisa memandang masa depan dengan tersenyum optimis.

\section{Relevansi Nilai-Nilai Pendidikan Kejhung Madura bagi Penanaman Karakter}

Karakter merupakan aplikasi nilai kebaikan dalam bentuk tindakan dan tingkah laku. Faktor yang memengaruhi terbentuknya karakter adalah sikap moral,agama, personal, sopan santun, tata karma pada lingkungan atau masyarakat tertentu. Oleh karena itu, penanaman karakter dapat dilakukan dengan cara mensosialisasikan, menginternalisasi nilai-nilai yang bersumber pada budaya setempat dan membangun budi pekerti manusia (Sunaryadi, 2012:260).

Penanaman nilai-nilai luhur berhubungan dengan pembinaan mental seseorang sehingga terbentuk karakter yang baik. nilainilai yang bersumber dari budaya, agama, keyakinan, dan lain-lain. Penanaman karakter dapat dilakukan di lingkungan keluarga, di pendidikan formal maupun nonformal, serta dalam kegiatan masyarakat. Oleh karena itu, nilai-nilai luhur perlu disosialisasikan yang meliputi nilai kebaikan maupun menetralisir nilai yang tidak baik menjadi baik.

Kejhung Madura merupakan kesenian yang sarat dengan nilai-nilai seperti nilai religius, nilai budaya, nilai tata karma, etika, sopan santun, dan sebagainya. Sastra lisan ini memang tidak banyak yang meminati, namun nilai-nilai yang terkandung memiliki 
relevansi untuk menanamkan nilai-nilai luhur untuk membentuk karakter masyarakat. Penanaman karakter dapat dilakukan dengan melalui pertunjukan atau dapat diadopsi dalam bentuk baru dengan media yang disesuaikan dengan kondisi perkembangan teknologi pada saat ini. Media visiual dapat diwujudkan dalam berbagai teknik dengan memasukkan nilai-nilai pendidikan karakter di dalam kejhungannya. Penanaman karakter juga dapat dilakukan melalui pendidikan seni budaya, pendidikan muatan lokal, pendidikan sastra dengan memasukkan nilai-nilai karakter budaya lokal dan dapat disosialisasi dan ditanamkan kepada anak didik di sekolah.

\section{SIMPULAN}

Tradisi lisan kèjhung juga merupakan bagian dari upacara adat, pesta-pesta, sebagai sastra lama, kèjhung sebagai sebagaimana pantun berisi nilai-nilai budaya dari kehidupan dari masyarakat. Nilai-nilai pendidikan yang terkadung dalam kèjhung Madura tersebut meliputi (1) nilai religius, (2) nilai budaya, (3) nilai sosial, (4) nilai personal.

Penanaman nilai nilai luhur berhubungan dengan pembinaan mental seseorang sehingga terbentuk karakter yang baik. nilainilai yang bersumber dari budaya, agama, keyakinan, dan lain-lain. Penanaman karakter dapat dilakukan di lingkungan keluarga, di pendidikan formal maupun nonformal, serta dalam kegiatan masyarakat. Oleh karena itu, nilai-nilai luhur perlu disosialisasikan yang meliputi nilai kebaikan maupun menetralisir nilai yang tidak baik menjadi baik. Penanaman karakter juga dapat dilakukan melalui pendidikan seni budaya, pendidikan muatan lokal, pendidikan sastra dengan memasukkan nilai-nilai karakter budaya lokal dan dapat disosialisasi dan ditanamkan kepada anak didik di sekolah.

\section{DAFTAR PUSTAKA}

Badri, M. 2015. "Dimensi Asrè Tuturan Kèjhung sebagai Ekspresi Pendidikan Karakter Warisan Madura-Melayu" Seminar Internasional UNISMA Malang.

Bouvier, Helene. 2002. Lebur: Seni Musik dan Pertunjukan dalam Masyarakat Madura. Penerjemah: Rahayu S. Hidayat dan Jean Counteau. Jakarta: Forum Jakarta Paris Ecole Francaise d'Extreme-Orient Yayasan Asosiasi Tradisi Lisan Yayasan Obor Indonesia.

Britton, Karl. 2007. Philoshopy and The Meaning of Life. Terjemahan. Muzir, Inyiak Ridwan. 2010. Yoyakarta: ArRuz Media.

Busri, Hasan. 2010. Simbol Budaya Madura dalam Cerita Rakyat Madura. Disertasi Tidak Diterbitkan. Program Pascasarjana Universitas Negeri Malang.

Mistortoify, Zulkarnain. 2010. Kèjhungan: Gaya Nyanyian Madura, dalam Pemaknaan Masyarakat Madura Barat. Disertasi Tidak Diterbitkan. Program Pascasarjana Universitas Gadjah Mada.

Palmer, E. Richard. 1969. Hermeneutics: Interpretation Theory in Schleirmacher, Dilthey, Heidegger, and Gadamer. Terjemahan.

Masnur, Hery dan Damanhuri Muhammad. 2005. Hermeneutika: Teori Baru Mengenai Interpretasi. Yogyakarta: Pustaka Pelajar. 